\title{
A PRODUÇÃO ACADÊMICA SOBRE O SERVIÇO SOCIAL NA GESTÃO DE PROJETOS SOCIAIS
}

\section{ARTIGO ORIGINAL}

GIRALDELI, Vanessa Santos ${ }^{1}$

GIRALDELI, Vanessa Santos. A produção acadêmica sobre o serviço social na gestão de projetos sociais. Revista Científica Multidisciplinar Núcleo do Conhecimento. Ano. 06, Ed. 12, Vol. 10, pp. 99-117. Dezembro de 2021. ISSN: 2448-0959, Link de acesso: https://www.nucleodoconhecimento.com.br/cienciassociais/social-na-gestao, DOI: 10.32749/nucleodoconhecimento.com.br/cienciassociais/social-na-gestao

\section{RESUMO}

A gestão de projetos sociais é uma área potencial de atuação dos(as) assistentes sociais, por se configurar em um espaço de reflexão crítica sobre a intervenção social, sendo uma estratégia a ser utilizada por estes profissionais na luta pela garantia dos direitos e pela qualidade do serviço prestado. Diante da relevância deste tema para o Serviço Social, busca-se responder à seguinte questão norteadora: Existe produção acadêmica sobre o tema Serviço Social e gestão de projetos sociais? O trabalho tem como objetivo analisar como o Serviço Social se aproxima do campo da gestão de projetos sociais, do ponto de vista da produção acadêmica da profissão sobre o tema. Recorreu-se à revisão bibliográfica para fundamentação teórica acerca da dimensão interventiva da prática profissional, do universo da gestão de projetos sociais e das competências e atribuições do Serviço Social nesse universo. Também se utilizou da pesquisa quantitativa exploratória para identificar a existência de trabalhos acadêmicos que tratam do tema Serviço Social e gestão de projetos sociais. Os resultados demonstraram que a produção

\footnotetext{
${ }^{1}$ Pós-graduação Latu Sensu Serviço Social em situações de desastre (em andamento). Pós-graduação Latu Sensu em Gestão de Projetos Sociais; MBA em Gestão de Pessoas; Graduação em Serviço Social. ORCID: 00000002-5902-9575.
}

RC: 104052

Disponível em: https://www.nucleodoconhecimento.com.br/ciencias-sociais/social-nagestao 
acadêmica do Serviço Social especificamente no âmbito da gestão de projetos sociais ainda é tímida ou não está suficientemente democratizada no contexto da internet. Conclui-se que a gestão de projetos sociais ainda precisa ser mais bem apropriada pelos(as) assistentes sociais, de forma que o conhecimento decorrente do debate no interior do Serviço Social possa ser transformado em trabalhos acadêmicos que subsidiem os profissionais a atuarem no âmbito da gestão, apropriando-se dele.

Palavras-chave: Serviço Social, Produção acadêmica, Gestão, Projetos sociais.

\section{INTRODUÇÃO}

A administração de programas e projetos é uma das competências do(a) assistente social, estabelecida na Lei de Regulamentação do Serviço Social, Lei 8.662/1993. Nos últimos tempos, o contexto de avanço do neoliberalismo no âmbito do Estado e a consequente redução do orçamento público para custeio das políticas sociais exige das instituições públicas e privadas o aprimoramento da sua capacidade de planejamento e gestão de suas ações. Não à toa, inúmeros cursos no âmbito da gestão de projetos sociais estão disponíveis para capacitar diversos profissionais, entre eles, os(as) assistentes sociais.

O Serviço Social, sendo uma profissão que historicamente ocupa um importante papel por sua dimensão interventiva, ao estabelecer ações de elaboração, planejamento, coordenação, execução, gerenciamento e avaliação de políticas, programas e projetos nas competências e atribuições privativas estabelecidas na Lei 8.662/1993, está reconhecendo a importância de uma atuação crítica, reflexiva, em consonância com o projeto ético-político profissional. Tal reconhecimento cria condições para que os profissionais superem a condição de meros executores terminais das políticas sociais, e ocupem também espaços de gestão, de forma a contribuir para a ampliação dos direitos da classe trabalhadora. A gestão de projetos sociais, portanto, é um importante espaço de atuação para o enfrentamento da questão social.

RC: 104052

Disponível em: https://www.nucleodoconhecimento.com.br/ciencias-sociais/social-nagestao 
Nesse sentido, o presente artigo tem por objetivo analisar como o Serviço Social se aproxima do campo da gestão de projetos sociais, do ponto de vista da produção acadêmica da profissão sobre o tema. Para tanto, busca-se responder à seguinte questão norteadora: Existe produção acadêmica sobre o tema Serviço Social e gestão de projetos sociais?

Recorreu-se à revisão bibliográfica para fundamentação teórica acerca da dimensão interventiva da prática profissional, do universo da gestão de projetos sociais e das competências e atribuições do Serviço Social nesse universo.

Também se utilizou da pesquisa quantitativa para identificar a existência de trabalhos acadêmicos que tratam do tema Serviço Social e gestão de projetos sociais.

As fontes de informação utilizadas para a pesquisa quantitativa foram o site de buscas do Google (https://www.google.com.br/) e site da Scielo Brasil (https://www.scielo.br/). A opção por tais fontes de dados se deu por reconhecer que a internet tem sido um espaço de democratização do conhecimento e pode ser um aliado da profissão quando se trata de compartilhar as experiências das mais diversas áreas de atuação profissional, entre elas, a área de gestão de projetos sociais. Nesse sentido, a análise dos dados disponíveis na internet pode auxiliar na compreensão acerca da relação do serviço social com a gestão de projetos sociais do ponto de vista da produção acadêmica, objeto de análise deste trabalho.

A coleta de dados foi realizada no mês de novembro/2021. Buscou-se localizar trabalhos acadêmicos disponíveis no site de buscas do Google e site da Scielo Brasil, que, de alguma forma, sinalizaram o tema "serviço social e gestão de projetos sociais". Para esta busca, utilizou-se como critério de análise e seleção o título dos trabalhos. No total, foram localizados dezesseis trabalhos acadêmicos cujos títulos e resumos se aproximaram do tema pesquisado, em uma busca realizada em dezessete páginas do Google. Considerando que da página treze à página dezessete a busca retornou zero trabalhos que atendessem ao critério de análise 
adotado, compreendeu-se que a amostra foi suficiente para a pesquisa. Ao aplicar a mesma metodologia para o site da Scielo Brasil, a pesquisa retornou zero resultados. Não houve delimitação de período pesquisado para essa etapa.

\section{A DIMENSÃO INTERVENTIVA DA PRÁTICA PROFISSIONAL DO(A) ASSISTENTE SOCIAL}

O Serviço Social é uma profissão, por natureza, eminentemente interventiva. De acordo com lamamoto e Carvalho (2007, p. 71), a profissão deve ser compreendida como um tipo de especialização do trabalho coletivo inscrita na divisão social do trabalho, que participa do processo de reprodução das relações sociais. Em outras palavras, o Serviço Social participa do processo de "reprodução de determinado modo de vida".

Para compreender a dimensão interventiva do Serviço Social é necessário, portanto, compreender que a atuação profissional do assistente social acontece nas "contradições inerentes à constituição da sociedade capitalista" (TORRES, 2016, p. 57). Além disso, é importante reconhecer que é na dimensão interventiva que se materializam as dimensões constitutivas do Serviço Social: ético-política, teóricometodológica e técnico-operativa (TORRES, 2016, p. 70).

Apesar de ser uma dimensão que se revela como lócus do fazer profissional do assistente social (TORRES, 2016, p.70), a intervenção profissional em grande medida "realiza-se à margem das instâncias de tomada de decisões acerca das políticas sociais", o que indica o caráter de subalternidade dado à intervenção profissional (GUERRA, 2014, p. 216).

Aqui há que se considerar que o cotidiano profissional se realiza pela inserção do assistente social na execução terminal das políticas sociais, cujo formato limita ou potencializa a sua ação profissional. Neste sentido, o padrão atual de políticas sociais privatista, mercantilista e assistencialista, que fragmenta, segmenta e setoriza as necessidades e categorias sociais, predispõe um tipo de intervenção: pontual, focalizada, imediata, burocrática, mimética, repetitiva, pragmática e eminentemente instrumental, exigindo pouca qualificação para responder às demandas imediatas, condicionando o

RC: 104052

Disponível em: https://www.nucleodoconhecimento.com.br/ciencias-sociais/social-nagestao 
exercício profissional às características e dinâmica do cotidiano e se limitando a ele (GUERRA, 2017, p. 58).

Todavia, torna-se fundamental reconhecer que a atuação profissional não deve se restringir apenas às atividades ligadas à abordagem direta da população atendida, mas atuar "na pesquisa e produção de conhecimento, administração, planejamento, supervisão, consultoria e gestão de políticas, programas e projetos na área social" (YAZBEK, 2017, p. 10).

Nesse sentido, apropriar-se das possibilidades de atuação da profissão, reconhecendo as contradições às quais ela atravessa e é atravessada no processo de produção e reprodução das relações sociais, pode ser um caminho para romper com a subalternidade histórica que caracteriza tal dimensão. E uma dessas possibilidades de atuação é o universo da gestão de projetos sociais.

\section{O UNIVERSO DA GESTÃO DE PROJETOS SOCIAIS}

Inicialmente, é relevante compreender o conceito de projetos sociais. Para Armani (2009, p.18), "Basicamente, um projeto é uma ação social planejada, estruturada em objetivos, resultados e atividades baseados em uma quantidade limitada de recursos (humanos, materiais e financeiros) e de tempo", que "só fazem sentido na medida em que fazem parte de programas e/ou políticas mais amplas".

A partir de tal conceito, vale a pena refletir sobre o que significa planejar. Para Baptista (2003, p. 13),

O termo "planejamento", na perspectiva lógico-racional, refere-se ao processo permanente e metódico de abordagem racional e científica de questões que se colocam no mundo social. Enquanto processo permanente, supõe ação contínua sobre um conjunto dinâmico de situações em um determinado momento histórico. Como processo metódico de abordagem racional e científica, supõe uma sequência de atos decisórios, ordenados em momentos definidos e baseados em conhecimentos teóricos, científicos e técnicos.

A dimensão política do planejamento decorre do fato de que ele é um processo contínuo de tomadas de decisões, inscritas nas relações de poder, o que caracteriza ou envolve uma função política.

RC: 104052

Disponível em: https://www.nucleodoconhecimento.com.br/ciencias-sociais/social-nagestao 
No contexto do Serviço Social, Mioto e Nogueira (2009, p. 287) sinalizam um aspecto muito relevante quando se trata de planejamento: a importância de um processo contínuo do ato de pensar racionalmente, para que se garanta a possibilidade de um "repensar contínuo" sobre o trabalho desenvolvido, como estratégia de superar práticas burocratizadas, rotineiras e repetitivas. Além disso, o ato de planejar, segundo as autoras, nos permite "formalizar a articulação intrínseca entre as dimensões constituintes do fazer profissional".

O processo de planejamento se consolida nos seguintes instrumentos: plano, programa e projeto.

Esses instrumentos marcam e/ou registram diferentes níveis de decisão e maior ou menor aproximação com a ação. Guardam entre si coerência e relativo grau de interdependência. São documentos que formalizam as decisões tomadas em relação ao que se pretende (MIOTO; NOGUEIRA, 2009, p. 288)

Sendo assim, o projeto social deve ser compreendido como um instrumento de planejamento, com potencial de transformação da realidade, e contém uma intencionalidade. Dessa forma, não pode resumir-se ao documento formal apresentado apenas quando se deseja captar recursos para determinada ação, porque projetos sociais podem trazer contribuições importantes para a resolução dos problemas sociais, como por exemplo:

eles podem trazer certas questões para o conhecimento e o debate público; eles podem promover a experimentação e a inovação metodológica; podem fortalecer organizações comunitárias e a participação na vida política e social; eles podem também ajudar na recuperação da autoestima e da dignidade humana de setores sociais excluídos; podem ainda contribuir para a defesa de direitos adquiridos ou para a criação de novos direitos [...] (ARMANI, 2009, p. 15).

Os projetos sociais, se bem elaborados, podem tornar-se importantes instrumentos para aumentar as chances de sucesso de uma intervenção social. Contudo, há que se reconhecer que a atuação profissional utilizando apenas este instrumento não é suficiente para resolver os problemas sociais, sendo necessário investir em políticas públicas adequadas, com recursos suficientes (ARMANI, 2009).

Disponível em: https://www.nucleodoconhecimento.com.br/ciencias-sociais/social-nagestao 
Em geral, as fases de planejamento e execução de projetos constituem o cotidiano profissional de diversos assistentes sociais (MIOTO; NOGUEIRA, 2009), uma vez que "o projeto concretiza as decisões, sinaliza para ações que operacionalizam as intenções e objetivos contidos nos planos" (MIOTO; NOGUEIRA, 2009, p. 291). Mas, em geral, a utilização desse instrumento acontece de maneira implícita, sem uma "expressão formal" (MIOTO; NOGUEIRA, 2009, p. 291), ou seja, sem a existência de um plano ou programa expressos em um documento que subsidie o cotidiano de trabalho e as ações profissionais de maneira clara, organizada e com o devido planejamento.

Até aqui se ressaltou a importância de uma prática planejada que contribua para uma atuação crítica e propositiva que repercuta positivamente na qualidade do serviço prestado. Porém, é salutar considerar que o ato de planejar, por si só, não garante que as decisões tomadas para intervir em determinado contexto serão efetivamente materializadas, pois essa é apenas uma das etapas do ciclo de vida de um projeto. Em outras palavras, elaborar bons projetos não garantirá o alcance os objetivos traçados. Para isso, existe uma segunda etapa desse universo, que aqui denominamos gestão do planejamento.

Gerenciar é estabelecer ou interpretar objetivos e depois planejar, organizar, dirigir e controlar as atividades e os recursos de uma organização de forma coordenada, visando o alcance dos objetivos previamente estabelecidos. [...]Gerenciar é, portanto, orientar a dinâmica da organização, ação necessária porque, sem ela, as pessoas trabalhariam para a obtenção de seus próprios objetivos, desperdiçando esforços. (SOUZA, 2001, p. 107).

A gestão de projetos consiste na aplicação de técnicas, conhecimentos e habilidades para o alcance dos objetivos traçados no projeto. Ou seja, por meio do gerenciamento e organização das etapas para a execução do que foi estabelecido no projeto, aumenta-se a chance de os resultados esperados serem alcançados. $\mathrm{O}$ gerenciamento é aqui compreendido como uma etapa na qual se realiza o Monitoramento e Avaliação (M\&A) da execução do projeto (ARMANI, 2009).

O processo de Monitoramento e Avaliação de um projeto é definido como o conjunto dos procedimentos de acompanhamento e análise realizados ao

RC: 104052

Disponível em: https://www.nucleodoconhecimento.com.br/ciencias-sociais/social-nagestao 
longo da sua implementação, com o propósito de checar se as Atividades e Resultados realizados correspondem ao que foi planejado (M) e se os Objetivos previstos estão sendo alcançados (A) (ARMANI, 2009, p. 69).

O monitoramento e a avaliação devem cumprir não só a função de controle sobre o alcance dos resultados e objetivos, mas, especialmente, permitir aos executores do projeto um espaço de reflexão crítica e aprendizado (ARMANI, 2009).

Por esse motivo, a gestão de projetos sociais é tema relevante que deve ser inserido no debate profissional dos(as) assistentes sociais, uma vez que se configura em um espaço de reflexão crítica sobre a intervenção social, sendo mais uma estratégia a ser utilizada pelos(as) assistentes sociais na luta pela garantia dos direitos e pela qualidade do serviço prestado. Nas palavras de Vasconcelos (2009, p. 258):

[...] é no planejamento do Serviço Social e das ações que os assistentes sociais/ equipes se preparam para trabalhar. O produto resultante do planejamento não é um simples documento a ser consultado. É um instrumento de luta, de negociação, de registro da prática. Se a formação profissional oferece os instrumentos teóricos para captar o movimento da realidade social é ao projetar suas ações que os profissionais se transformam em "recurso vivo", podendo, assim, contribuir com os usuários na busca por transformação das suas condições de vida e de trabalho (grifos do autor).

\section{ATRIBUIÇÕES E COMPETÊNCIAS DO(A) ASSISTENTE SOCIAL E A GESTÃO DE PROJETOS SOCIAIS}

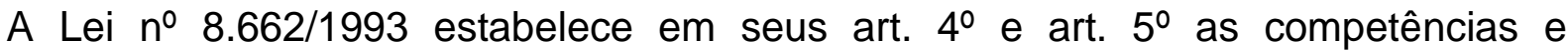
atribuições privativas do(a) assistente social. Ao analisar os referidos artigos, notase que das onze competências atribuídas a este profissional, sete (incisos I, II, VI, VII, VIII, IX e X) referem-se a ações de elaboração, planejamento, coordenação, execução, gerenciamento e avaliação de políticas, programas e projetos.

Art. 4ํㅡㄹ Constituem competências do Assistente Social:

I - Elaborar, implementar, executar e avaliar políticas sociais junto a órgãos da administração pública, direta ou indireta, empresas, entidades e organizações populares;

RC: 104052

Disponível em: https://www.nucleodoconhecimento.com.br/ciencias-sociais/social-nagestao 
II - Elaborar, coordenar, executar e avaliar planos, programas e projetos que sejam do âmbito de atuação do Serviço Social com participação da sociedade civil;

III - encaminhar providências, e prestar orientação social a indivíduos, grupos e à população;

IV - (Vetado);

V - Orientar indivíduos e grupos de diferentes segmentos sociais no sentido de identificar recursos e de fazer uso dos mesmos no atendimento e na defesa de seus direitos;

VI - Planejar, organizar e administrar benefícios e Serviços Sociais;

VII - planejar, executar e avaliar pesquisas que possam contribuir para a análise da realidade social e para subsidiar ações profissionais;

VIII - prestar assessoria e consultoria a órgãos da administração pública direta e indireta, empresas privadas e outras entidades, com relação às matérias relacionadas no inciso II deste artigo;

IX - Prestar assessoria e apoio aos movimentos sociais em matéria relacionada às políticas sociais, no exercício e na defesa dos direitos civis, políticos e sociais da coletividade;

X - Planejamento, organização e administração de Serviços Sociais e de Unidade de Serviço Social;

XI - realizar estudos socioeconômicos com os usuários para fins de benefícios e serviços sociais junto a órgãos da administração pública direta e indireta, empresas privadas e outras entidades (BRASIL, 1993, destaques nossos).

Da mesma forma, ao analisar as atribuições privativas contidas no mesmo referencial legal, identifica-se que oito das treze atribuições elencadas também se referem a ações de assessoria, planejamento, execução, gerenciamento e direção (incisos I, II, III, VII, VIII, X, XII e XIII).

Art. 5ํㅡㄴ Constituem atribuições privativas do Assistente Social:

I - Coordenar, elaborar, executar, supervisionar e avaliar estudos, pesquisas, planos, programas e projetos na área de Serviço Social;

RC: 104052

Disponível em: https://www.nucleodoconhecimento.com.br/ciencias-sociais/social-nagestao 
II - Planejar, organizar e administrar programas e projetos em Unidade de Serviço Social;

III - assessoria e consultoria e órgãos da Administração Pública direta e indireta, empresas privadas e outras entidades, em matéria de Serviço Social;

IV - Realizar vistorias, perícias técnicas, laudos periciais, informações e pareceres sobre a matéria de Serviço Social;

V - Assumir, no magistério de Serviço Social tanto a nível de graduação como pós-graduação, disciplinas e funções que exijam conhecimentos próprios e adquiridos em curso de formação regular;

VI - Treinamento, avaliação e supervisão direta de estagiários de Serviço Social;

VII - dirigir e coordenar Unidades de Ensino e Cursos de Serviço Social, de graduação e pós-graduação;

VIII - dirigir e coordenar associações, núcleos, centros de estudo e de pesquisa em Serviço Social;

IX - Elaborar provas, presidir e compor bancas de exames e comissões julgadoras de concursos ou outras formas de seleção para Assistentes Sociais, ou onde sejam aferidos conhecimentos inerentes ao Serviço Social;

X - Coordenar seminários, encontros, congressos e eventos assemelhados sobre assuntos de Serviço Social;

XI - fiscalizar o exercício profissional através dos Conselhos Federal e Regionais;

XII - dirigir serviços técnicos de Serviço Social em entidades públicas ou privadas;

XIII - ocupar cargos e funções de direção e fiscalização da gestão financeira em órgãos e entidades representativas da categoria profissional (BRASIL, 1993, destaques nossos).

O que se observa é que as normativas profissionais direcionam o Serviço Social para uma atuação crítica, teleológica, com intencionalidade. As dimensões éticopolítica, teórico-metodológica e técnico-operativa do Serviço Social o habilitam tecnicamente a atuar não só no planejamento e elaboração de projetos, programas e políticas, mas também no gerenciamento de projetos sociais.

RC: 104052

Disponível em: https://www.nucleodoconhecimento.com.br/ciencias-sociais/social-nagestao 
Considerando a importância e relevância que a gestão de projetos sociais possui para o Serviço Social, conforme demonstrado até o momento, nossa intenção é identificar se, em alguma medida, o tema gestão de projetos sociais no âmbito da atuação dos(as) assistentes sociais tem recebido a atenção desses profissionais em suas produções acadêmicas. Para isso, recorremos à pesquisa quantitativa cujos resultados serão apresentados a seguir.

\section{A GESTÃO DE PROJETOS SOCIAIS NA PRODUÇÃO ACADÊMICA DO SERVIÇO SOCIAL}

A pesquisa quantitativa realizada em novembro/2021 consistiu no levantamento de dados por meio do site de buscas Google, com a finalidade identificar e quantificar as produções acadêmicas que tratam do tema "serviço social e gestão de projetos sociais" disponíveis na internet. No total, dezessete páginas do Google foram analisadas e dezesseis trabalhos acadêmicos foram localizados, conforme tabela a seguir.

Tabela 1 - Relação de trabalhos acadêmicos localizados no site de buscas da Google em 15/11/2021.

\begin{tabular}{|l|l|l|}
\hline Ordem & $\begin{array}{l}\text { Título do trabalho } \\
\text { A importância da atuação do assistente social na gestão } \\
\text { de projetos sociais }\end{array}$ & Artigo \\
\hline 1 & $\begin{array}{l}\text { Serviço social e gestão de projetos sociais } \\
\text { Gerenciamento de projetos sociais: uma prática do } \\
\text { serviço social }\end{array}$ & Monografia \\
\hline 3 & $\begin{array}{l}\text { Atuação do assistente social na elaboração e gestão de } \\
\text { projetos sociais }\end{array}$ & Artigo \\
\hline 4 & $\begin{array}{l}\text { Atuação do serviço social em projetos sociais com } \\
\text { aposentados }\end{array}$ & Artigo \\
\hline 6 & A invisibilidade da área de projetos sociais no processo de & Artigo \\
\hline 5
\end{tabular}




\begin{tabular}{|c|c|c|}
\hline & formação e atuação profissional dos assistentes sociais & \\
\hline 7 & $\begin{array}{l}\text { Gestão de serviços sociais: novas competências } \\
\text { profissionais? }\end{array}$ & Artigo \\
\hline 8 & $\begin{array}{l}\text { Serviço social: exercício profissional do assistente social } \\
\text { na gestão de políticas públicas }\end{array}$ & Artigo \\
\hline 9 & $\begin{array}{l}\text { Projetos de intervenção - instrumento para visualização } \\
\text { do trabalho do assistente social nos diferentes espaços } \\
\text { sócio ocupacionais }\end{array}$ & Artigo \\
\hline 10 & A gestão de projetos sociais: desafios multidisciplinares & Artigo \\
\hline 11 & $\begin{array}{l}\text { Atuação do serviço social no processo de gestão e } \\
\text { avaliação de políticas e programas sociais }\end{array}$ & Artigo \\
\hline 12 & $\begin{array}{l}\text { A atuação do assistente social na gestão municipal da } \\
\text { política pública de assistência social: desafios e } \\
\text { possibilidades. atuação do serviço social no processo de } \\
\text { gestão e avaliação de políticas e programas sociais }\end{array}$ & Artigo \\
\hline 13 & $\begin{array}{l}\text { A atuação do assistente social no planejamento e gestão } \\
\text { das políticas de assistência social e saúde no município } \\
\text { de Aracaju-SE }\end{array}$ & Dissertação \\
\hline 14 & $\begin{array}{l}\text { A inserção do profissional assistente social na gestão da } \\
\text { política de assistência social na particularidade riostrense. }\end{array}$ & Monografia \\
\hline 15 & $\begin{array}{l}\text { A efetividade da gestão social e a prática do assistente } \\
\text { social na proteção social especial de média complexidade }\end{array}$ & Artigo \\
\hline 16 & $\begin{array}{l}\text { Sistematização, planejamento e avaliação das ações dos } \\
\text { assistentes sociais no campo da saúde }\end{array}$ & Artigo \\
\hline
\end{tabular}

Fonte: Site de pesquisa do Google. Elaboração própria.

Também tentamos localizar trabalhos acadêmicos na base de dados da Scielo Brasil com as palavras-chave "serviço social e gestão de projetos sociais" ou "assistente social e gestão de projetos sociais". Todavia, nenhum artigo foi localizado. 
Do total de trabalhos disponíveis na internet, sete $(43,75 \%)$ mencionam acerca da gestão de projetos sociais e, portanto, atendem integralmente ao termo pesquisado "Serviço Social e gestão de projetos sociais", entre os quais apenas um enquadra-se na categoria monografia. Os outros nove trabalhos $(56,25 \%)$ tratam do Serviço Social e sua atuação no âmbito da gestão de maneira ampla, sem um recorte para o contexto dos projetos sociais, tratando sobre gestão dos serviços sociais, gestão social, sistematização, planejamento e avaliação das ações, gestão de políticas e programas sociais. Além disso, nenhuma dissertação ou tese foi encontrada a respeito da atuação do Serviço Social na gestão de projetos sociais.

Tabela 2 - Quantitativo de trabalhos acadêmicos localizados no site de buscas da Google em 15/11/2021.

\begin{tabular}{|c|c|c|c|c|c|}
\hline Temas/Categorias & Monografia & Artigo & Dissertação & Tese & Total \\
\hline $\begin{array}{l}\text { Serviço Social e gestão } \\
\text { de projetos sociais }\end{array}$ & $\begin{array}{l}1 \\
(6,25 \%)\end{array}$ & $\begin{array}{l}6 \\
(37,5 \%)\end{array}$ & $\begin{array}{l}0 \\
(0 \%)\end{array}$ & $\begin{array}{l}0 \\
(0 \%)\end{array}$ & $\begin{array}{l}7 \\
(43,75 \%)\end{array}$ \\
\hline Serviço Social e gestão & $\begin{array}{l}1 \\
(6,25 \%)\end{array}$ & $\begin{array}{l}7 \\
(43,75 \%)\end{array}$ & $\begin{array}{l}1 \\
(6,25 \%)\end{array}$ & $\begin{array}{l}0 \\
(0 \%)\end{array}$ & $\begin{array}{l}9 \\
(56,25 \%)\end{array}$ \\
\hline Total & $\begin{array}{l}2 \\
(12,5 \%)\end{array}$ & $\begin{array}{l}13 \\
(81,25 \%)\end{array}$ & $\begin{array}{l}1 \\
(6,25 \%)\end{array}$ & $\begin{array}{l}0 \\
(0 \%)\end{array}$ & $\begin{array}{l}16 \\
(100 \%)\end{array}$ \\
\hline
\end{tabular}

Fonte: Tabela 1. Elaboração própria.

Os resultados demonstraram que os profissionais têm produzido estudos sobre a atuação do Serviço Social no contexto dos projetos sociais, contudo, no que diz respeito à especificidade da gestão de projetos sociais (monitoramento e avaliação), poucos estudos sobre o tema foram encontrados disponíveis na internet em forma de trabalhos acadêmicos. Isso nos leva a afirmar que a produção acadêmica do Serviço Social no contexto da gestão e, mais especificamente, no âmbito da gestão de projetos sociais ainda é tímida ou não está suficientemente democratizada no 
contexto da internet. Apenas sete trabalhos acadêmicos foram encontrados no site de buscas do Google com relação direta com o tema Serviço Social e gestão de projetos.

A análise dos trabalhos permite compreender que o conhecimento acadêmico acerca da gestão de projetos, a partir da leitura crítica do(a) assistente social é importante para a qualificação permanente, tendo em vista que "um profissional qualificado, atuando na gestão, consegue aplicar melhor suas técnicas, agregando resultado ao projeto" (SILVA, 2021, n.p.).

Além disso, é preciso compreender que fazer gestão de projetos sociais não significa burocratizar e engessar rotinas administrativas, sem realizar um processo contínuo de reflexão sobre o fazer profissional.

No âmbito da gestão social, portanto, é essencial superar a burocratização no planejamento e operação de projetos para atribuir-lhes dinamicidade e versatilidade, transitando para esquemas de gestão de projetos com maior flexibilidade e, ainda, garantindo sua continuidade, sua autossutentabilidade através de modelos inovadores de avaliação (ABREU, 2020, p. 1).

Considerando as diversas transformações no mercado de trabalho e o compromisso ético-político assumido pelos profissionais, a "atuação de assistentes sociais na elaboração e gestão de projetos sociais possibilita aos profissionais uma experiência indispensável para o crescimento e enriquecimento profissional" (SOUZA, 2016, n.p.), uma vez que "refletir as práticas da profissão e construir um perfil profissional baseado nos conceitos de gestão, torna-se um diferencial para a inclusão no mercado" (SILVA, 2016, n.p.).

Lima; Rodrigues e Silva (2019, n.p.) sinalizam "[...] que os projetos sociais são berços de alternativas para o Serviço Social, que potencializam a viabilização dos direitos sociais dos/as usuários/as".

Assim a utilização desse instrumental no dia a dia faz com que o trabalho profissional se qualifique permanentemente, pois favorece o acompanhamento das ações; sua avaliação, não só do ponto de vista dos

RC: 104052

Disponível em: https://www.nucleodoconhecimento.com.br/ciencias-sociais/social-nagestao 
resultados institucionais esperados, mas dos compromissos profissionais construídos (SALVADOR, 2018, p. 4).

Portanto, os assistentes sociais, no âmbito da gestão, devem atuar "como articuladores e negociadores dos interesses das classes subalternas por intermédio do Estado para atender e responder de maneira efetiva as condições essenciais ao exercício da cidadania" (CARDOSO; FAGUNDES, 2013, n.p.)

Para tanto, Torres e Lanza (2012, p. 197) apontam que:

esse exercício requer do profissional um conjunto de saberes que o possibilita reconhecer as determinações constitutivas desse campo profissional, dentre elas: a identificação do modo como opera a relação teoria e prática; os conhecimentos que a orientam e a interpretação dos desafios da gestão social como possibilidade de (re)construir e qualificar as respostas profissionais.

Portanto, "a intervenção profissional nesse campo, supõe competência teórica, política e técnica fundamentadas no Código de Ética profissional, na lei que regulamenta a profissão" (SILVA, 2018, p. 561).

Os poucos estudiosos que tratam do tema afirmam que esse campo de atuação profissional tem crescido nos últimos anos.

Apesar de não ser um espaço novo de atuação dos assistentes sociais, essa participação na área do planejamento e gestão tem se ampliado nas últimas décadas, com novas dimensões e configurações, o que tem exigido um processo de qualificação permanente por parte do assistente social (HORA, 2014, p. 7).

Todavia, apesar de não ser um espaço novo de atuação, Cardoso e Fagundes (2013, n.p.) chamam a atenção para o caráter recente do debate sobre o assistente social enquanto gestor. Além disso, as autoras destacam que esse debate tem "ecoado principalmente com a organização da política de assistência social em um sistema descentralizado e participativo que é o SUAS" (CARDOSO; FAGUNDES, 2013, n.p.). Mas, apesar do esforço em ampliar tal discussão, especialmente no SUAS, "a participação dos Assistentes Sociais no âmbito da gestão da Política de Assistência no município é bastante reduzida" (MELLO, 2014, p. 56).

RC: 104052

Disponível em: https://www.nucleodoconhecimento.com.br/ciencias-sociais/social-nagestao 
Menezes (2000, p. 76) afirma que "[...] gerenciar projetos é um desafio", principalmente para o Serviço Social. Em primeiro lugar, "a pouca visibilidade que a área de gestão de projetos sociais ainda tem no âmbito acadêmico e profissional" (SILVA; SANTANA; OLIVEIRA, 2019, p. 1), sendo um tema pouco explorado nos cursos de graduação em Serviço Social (SILVA; SANTANA; OLIVEIRA, 2019, p. 10) é fator que contribui para tornar a gestão de projetos um desafio. Em consequência, é ainda um "tema de pouco arcabouço teórico" (SILVA; SANTANA; OLIVEIRA, 2019, p. 2).

Os cursos como Serviço Social, Ciências Sociais e Psicologia, que se encontram mais direcionados e próximos da atuação social, não trazem em sua maioria, em seus projetos pedagógicos, disciplinas que instrumentem para a gestão dos projetos, dificultando assim, o casamento necessário entre a militância, a boa intenção e os fatores de ordem prática que representam, na maior parte das vezes, impeditivos para que o projeto tenha êxito (CRUZ, 2011 , n.p.).

Conclui-se, portanto, que a produção acadêmica sobre a gestão de projetos ainda é um campo a ser explorado. Em resposta à questão norteadora, os resultados mostram que existe produção acadêmica sobre a atuação do Serviço Social no âmbito da gestão de projetos sociais, contudo, a produção é incipiente e o debate sobre o tema ainda é recente e embrionário. Há, portanto, uma área a ser explorada pelos assistentes sociais no campo da pesquisa acadêmica.

\section{CONSIDERAÇÕES FINAIS}

No referencial teórico adotado fica claro que o(a) assistente social possui competências e atribuições que the possibilitam atuar de maneira crítica, na busca da superação de uma atuação profissional limitada ao atendimento imediato da população, de forma fragmentada e acrítica. Também restou claro e evidente que esse movimento não depende exclusivamente do desejo do profissional, mas que requer uma transformação na estrutura de produção e reprodução das relações sociais vivenciadas no modo de produção capitalista.

RC: 104052

Disponível em: https://www.nucleodoconhecimento.com.br/ciencias-sociais/social-nagestao 
Mas, no universo de possibilidades existentes, a gestão de projetos sociais se coloca como um importante espaço de atuação profissional, tendo em vista que os projetos sociais permitem operacionalizar o planejamento, com chances de intervir na realidade e criar condições para provocar transformações que contribuam para o processo de consolidação de uma nova ordem societária.

As competências e atribuições privativas designadas pela Lei 8.662/93, a formação e o projeto ético-político do Serviço Social oferecem condições éticas, teóricas, técnicas e políticas para que $o(a)$ assistente social exerça atividades de coordenação, planejamento, gerenciamento e avaliação de políticas, programas e projetos sociais, na busca de fazer frente ao instituído, intervindo na realidade de maneira crítica e comprometida com a superação da ordem vigente.

$\mathrm{Na}$ tentativa de responder a questão norteadora sobre a existência de produção acadêmica sobre o tema Serviço Social e gestão de projetos sociais, a pesquisa quantitativa apresenta resultados que confirmam a existência de trabalhos acadêmicos sobre o tema pesquisado. Todavia, nos aponta um volume pequeno de produções acadêmicas, o que também se confirma na revisão bibliográfica.

Do total de trabalhos acadêmicos localizados na internet com alguma aproximação com o tema Serviço Social e projetos sociais, apenas sete trabalhos trazem reflexões sobre o tema gestão de projetos sociais. Os demais indicam reflexões sobre a atuação do Serviço Social no contexto da gestão de maneira ampla, sem relação direta com o campo da gestão de projetos sociais, mais especificamente com os processos de monitoramento e avaliação de projetos.

Conclui-se que, apesar da relevância e da necessidade do tema, a gestão de projetos sociais, do ponto de vista da produção acadêmica do Serviço Social, ainda não recebeu a atenção devida por parte dos(as) assistentes sociais no campo da pesquisa acadêmica, configurando-se como uma área que precisa ser melhor apropriada técnica, teórica e criticamente por estes(as) profissionais, de forma que a 
produção acadêmica contribua para a apropriação dessa área de trabalho, de forma que ela seja também ocupada pelos(as) assistentes sociais.

\section{REFERÊNCIAS BIBLIOGRÁFICAS}

ABREU, Natassis Souza de. Serviço Social e gestão de projetos sociais. Disponível em https://semanaacademica.org.br/system/files/artigos/servico_social_e_gestao_de_pr ojetos_sociais_artigo_0.pdf. Acesso em 15 nov. 2021.

ARMANI, Domingos. Como elaborar projetos? Guia prático para elaboração e gestão de projetos sociais. Porto Alegre: Tomo editorial, 2000.

BAPTISTA, Myrian Veras. Planejamento social: instrumentalidade e instrumentação. 2. ed. São Paulo, Veras Editora; Lisboa: CPIHTS, 2003.

BRASIL. Lei ํo 8.662/1993. Dispõe sobre a profissão de Assistente Social e dá outras providências. (Atualizada).

CARDOSO, Daniela Cima; FAGUNDES, Helenara Silveira. A atuação do assistente social na gestão municipal da política pública de assistência social: desafios e possibilidades. Congresso Catarinense de Assistentes Sociais, 2013. Disponivel em https://cress-sc.org.br/wp-content/uploads/2014/03/Aatua\%C3\%A7\%C3\%A3o-do-Assistente-Social-na-Gest\%C3\%A3o-Municipal-daPol\%C3\%ADtica-P\%C3\%BAblica-de-AS.pdf. Acesso em: 15 nov. 2021.

CRUZ, Myrt Thânia de Souza. A gestão de projetos sociais: desafios multidisciplinares. Apresentação de mesa redonda - 16ํㅡㄹ Encontro Nacional Abrapso, 2011.

Disponível

em https://www.encontro2011.abrapso.org.br/trabalho/view?q=YToyOntzOjY6InBhcmFtc yl7czozNjoiYToxOntzOjExOiJJRF9UUkFCQUxITyl7czo0OilyMjg4ljt9ljtzOjE6ImgiO3 M6MzI6ImFIMmNjNmVjNTc0ODk4NzVhODc3OGQ1YjJIZDY4Nzk5ljt9. Acesso em 15 nov. 2021.

RC: 104052

Disponível em: https://www.nucleodoconhecimento.com.br/ciencias-sociais/social-nagestao 
GUERRA, Yolanda. A dimensão técnico-operativa do exercício profissional. In: SANTOS, Cláudia Mônica dos; BACKX, Sandra; GUERRA, Yolanda (org.). A dimensão técnico-operativa no Serviço Social [livro eletrônico]: desafios contemporâneos. São Paulo, Cortez, 2017.

A instrumentalidade do serviço social. 10. ed. São Paulo. Cortez, 2014.

HORA, Michelle Marry Costa Campos. A atuação do assistente social no planejamento e gestão das políticas de assistência social e saúde no município de Aracaju-SE. Dissertação (Mestrado em Serviço Social. Universidade Federal de Sergipe, 2014.

Disponível

em https://ri.ufs.br/bitstream/riufs/6193/1/MICHELLE_MARRY_COSTA_CAMPOS_HOR A.pdf. Acesso em: 15 nov. 2021.

IAMAMOTO, Marilda Villela; CARVALHO, Raul de. Relações sociais e serviço social no Brasil: esboço de uma interpretação histórico-metodológica. 21. ed. São Paulo, Cortez; [Lima, Peru]: CELATS, 2007.

LIMA, Dorisângela Maria de Oliveira; RODRIGUES, Clesivania Xavier; SILVA, Joyce Beatriz Avelino. Atuação do Serviço Social em projetos sociais com aposentados. Anais do VI Congresso Internacional de Envelhecimento Humano, 2019. Disponível em

https://editorarealize.com.br/editora/anais/cieh/2019/TRABALHO_EV125_MD1_SA6 _ID33_22042019212709.pdf

MELLO, Igor Curty de. A inserção do profissional assistente social na gestão da Política de Assistência Social na particularidade riostrense. Monografia (Bacharelado em Serviço Social). Universidade Federal Fluminense, 2014.

MENEZES, Carla. Gerenciamento de projetos sociais: uma prática do serviço social. TCC (graduação) - Universidade Federal de Santa Catarina, Centro Sócio Econômico, Curso de Serviço Social. 2000. Disponível em https://repositorio.ufsc.br/handle/123456789/113818. Acesso em 15 nov. 2021.

RC: 104052

Disponível em: https://www.nucleodoconhecimento.com.br/ciencias-sociais/social-nagestao 
MIOTO, Regina Célia Tamaso; NOGUEIRA, Vera Maria Ribeiro. Sistematização, planejamento e avaliação das ações dos assistentes sociais no campo da saúde. In: MOTA, Ana Elisabete et al (org.). Serviço Social e Saúde: formação e Trabalho Profissional. 4.ed. São Paulo: Cortez, 2009.

NOGUEIRA, Vera Maria Ribeiro; SAUER, Mariane. A efetividade da gestão social e a prátca do assistente social na Proteção Social Especial de Média Complexidade. Revista Textos \& Contextos (Porto Alegre), v. 15, n. 2, p. 450 - 458, ago./dez. 2016. Disponível em https://revistaseletronicas.pucrs.br/ojs/index.php/fass/article/download/22604/15303/. Acesso em 15 nov. 2021.

SALVADOR, Maria E. Projetos de intervenção - instrumento para visualização do trabalho do assistente social nos diferentes espaços sócio ocupacionais. Anais do 16ํㅡㄹ Encontro Nacional de Pesquisadores em Serviço Social, 2018. Disponível em https://periodicos.ufes.br/abepss/article/view/22130/14646. Acesso em: 15 nov. 2021.

SILVA, Maria do Rosário de Fátima e. Atuação do Serviço Social no processo de gestão e avaliação de políticas e programas sociais. Revista de Políticas Públicas. 2018. Disponível em http://www.periodicoseletronicos.ufma.br/index.php/rppublica/article/download/9799/ 5754. Acesso em 15 nov. 2021.

SILVA, Simone Coutinho da. A Importância Da Atuação Do Assistente Social Na Gestão De Projetos Sociais. Revista Científica Multidisciplinar Núcleo do Conhecimento. Ano 06, Ed. 04, Vol. 02, pp. 72-87. Abril de 2021. Disponível em: https://www.nucleodoconhecimento.com.br/sociologia/projetos-sociais.

SILVA, Francisca Maria de Oliveira da; SANTANA, Valdismagna Novais de. OLIVEIRA, Monyelly Tuanny Soares. A invisibilidade da área de projetos sociais no processo de formação e atuação profissional dos assistentes sociais. 16을 
Congresso Brasileiro de Assistentes Sociais. 2019. Disponível em https://broseguini.bonino.com.br/ojs/index.php/CBAS/article/view/452/442.

SILVA, Rayoni Ralfh. Gestão de serviços sociais: novas competências profissionais? XXII Encontro de Iniciação Científica. Instituto Superior de Ciências Aplicadas - ISCA Faculdade/Limeira-SP, 2016. Disponível em https://www.usf.edu.br/ic_2016/pdf/projetos-independentes/GESTAO-DESERVICOS-SOCIAIS--novas-competencias-profissionais-1.pdf.

SOUZA, Maria Rosária de. Gestão administrativa e financeira de projetos sociais. In: ÁVILA, Célia M. de (coord.). Gestão de projetos sociais. $3^{\text {a }}$ ed. rev. - São Paulo : AAPCS - Associação de Apoio ao Programa Capacitação Solidária, 2001. Coleção gestores sociais.

SOUZA, Simone Moreira dos Santos. Atuação do assistente social na elaboração e gestão de projetos sociais. Educon, Aracaju, Volume 10, n. 01, p.9-10, set/2016. Disponível

em http://anais.educonse.com.br/2016/atuacao_do_assistente_social_na_elaboraca o_e_gestao_de_projetos_s.pdf.

TORRES, Mabel Mascarenhas. O exercício profissional do assistente social em questão: as publicações da área de Serviço Social. In: FORTI, Valéria; GUERRA, Yolanda (coordenadoras e organizadoras da série). Serviço social: temas, textos e contextos. 5. ed. rev. e ampl. Rio de Janeiro. Lumen Juris, 2016, p.55-76.

TORRES, Mascarenhas Mabel; LANZA, Liria Maria Bettiol. Serviço Social: exercício profissional do Assistente Social na gestão de políticas públicas. Argumentum, vol. 5, núm. 1, enero-junio, 2012, p. 197-215. Disponível em https://www.redalyc.org/pdf/4755/475547478013.pdf. Acesso em 15 nov. 2021.

VASCONCELOS, Ana Maria de. Serviço Social e práticas democráticas. In: MOTA, Ana Elisabete et al (org.). Serviço Social e Saúde: formação e Trabalho Profissional. 4.ed. São Paulo: Cortez, 2009. 
YAZBEK, Maria Carmelita. Prefácio à $2^{\underline{a}}$ edição. In: SANTOS, Cláudia Mônica dos; BACKX, Sandra; GUERRA, Yolanda (orgs.). A dimensão técnico-operativa no Serviço Social [livro eletrônico]: desafios contemporâneos. São Paulo, Cortez, 2017.

Enviado: Dezembro, 2021.

Aprovado: Dezembro, 2021. 